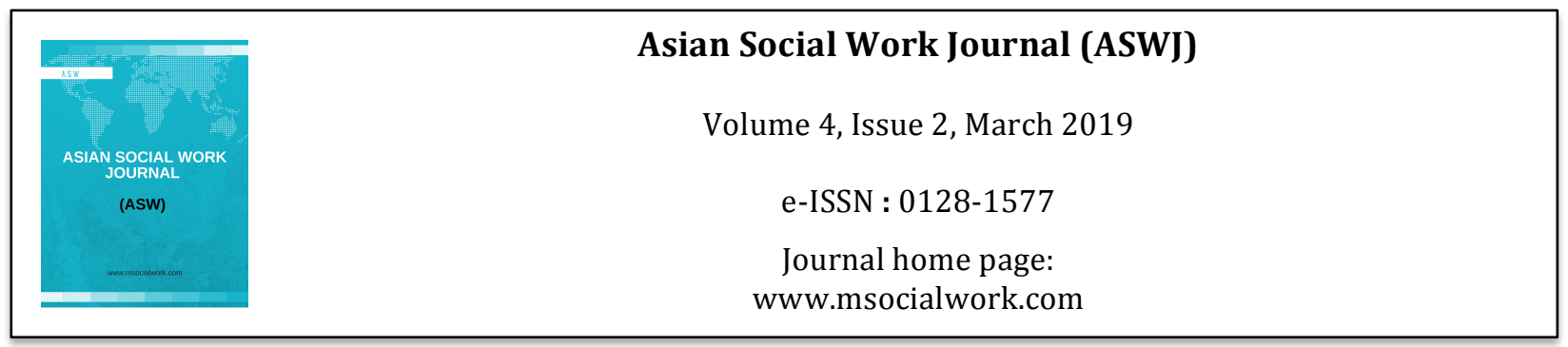

\title{
Coping with Drug Abuser in the Family: A Qualitative Study in Penang, Malaysia
}

\author{
Paramjit Singh Jamir Singh ${ }^{1}$, Azlinda Azman ${ }^{1}$, Syazwani Drani ${ }^{1}$ \\ ${ }^{1}$ Social Work Programme, School of Social Sciences, Universiti Sains Malaysia (USM) \\ Corrrespondence: Paramjit Singh Jamir Singh (paramjit@usm.my)
}

\begin{abstract}
Drug use in Malaysia has steadily increased over the past decade. Drug addiction does not only affect the addict, but it also impacts the lives of their family members. This qualitative study seeks to explore how the drug user's family members cope with the drug abuse problems in the family. A total of 20 respondents, acting as heads of their families, from the state of Penang, were interviewed. The findings indicated that the respondents utilized both problem-focused and emotion-focused coping strategies to cope with the drug addiction problems in the family. The respondents in this study also used both formal and informal social support systems to cope with the drug abuse problems caused by drug abuse within the family. This study suggests that the drug user's family members should engage themselves in self-help and support groups to find and learn about constructive coping strategies used by other families who have a similar experience in dealing with drug abuse problems in the family. In addition, by engaging themselves in self-help and support groups, it will help the drug user's family members gain emotional and social support from other drug user's family members.
\end{abstract}

Key words: drug abuse problems, family members, drug users, coping strategies.

\section{Introduction}

Cases with substance abuse especially on drug in Malaysia is currently on the rise. Substance abuse is a type of disease that directly impacts both neurological functioning and behavioural self-regulation of the abuser (Harbin \& Murphy, 2000). There are several whys and wherefores that lead to the substance abuse such as, being influenced and pressured by peers, to increase energy, to relief from stress, to relief from pain, to relax, to have an increased sense of self-esteem, to escape reality or rejection and for recreation. Nevertheless, not only the abuser were affected destructively, but also the abuser's family (Oreo \& Ozgul, 2007).

Drug abuse does not only affect harmfully to its abuser but also towards the whole family members in a way that their social life will be deteriorated due to stigma and discrimination from the society. Fisher (2007) found that the family members of drug abuser encounter severe problems in their societal relationship with the community. In addition, to support the aforementioned findings, a local research conducted by Singh and Azman (2015) also further agreed and found out that there were stigma and discriminations confronted by the family members of drug abuser in Malaysia especially in the state of Penang.

Oreo and Ozgul (2007) discovered that family members who owns a drug abuser often bump into stigma and discrimination from the local community such as, being ignored, humiliated and underestimated and, consequently, this led to an emotional problem towards the whole family 
members. According to Toumbourou, Blyth, Bamberg, and Forer (2001), prior to this situation, the family members often feel shocked, angry, scared, ashamed, guilty, powerless, giving up and in deep grievance whenever they were looked down and underestimated by the local community just because they have a drug abuser in the house. Unfortunately, this scenario has subsequently affected their social functioning and security in a very negative and destructing way.

Preceding to the aforementioned scenario, the family members of drug abuser frequently isolate themselves and feel reluctant to socialize with the public as they have to stand with the embarrassment of having a family member who is involved in drug abuse (Butler \& Baulds, 2005). According to Barnard (2005), the never end increasing stigma within the community had caused the family members of drug abuser to lose their self-confidence in confronting the public.

Morris (2010) highlighted that drug abuser family members also cause negative impacts on the emotion of other family members. Franco (2010) ascertained that parents who involved in drug abuse directly affect their children's emotion because these parents inclined towards domestic violence, child abuse and often being irresponsible towards their children. Furthermore, Franco also exposed that the affected children had experienced depression, anxiety, eating disorders and suicide attempts.

In addition to the explanation above, Franco (2010) reported that children of the parents who abused drugs are prone to getting involved in the same circumstances. On the other hand, Barnard (2005) findings were in line with Franco's (2010) as he also asserted that the risk of drug connexion among the family members of drug abuser is greater. Therefore, this qualitative study seeks to explore how do the family members of the drug abuser are coping with the drug addiction problems in the family.

\section{Methodology}

\section{Study Design}

This study adopt qualitative research method via in-depth interviews with the respondents. It is proven that in-depth interviews able to acquire a great amount of information based on real life experiences by the respondents. In most studies, in-depth interviews becomes the main instrument to attain first hand data or information while addressing specific and sensitive topics on individual which involves and relates to personal histories, perspectives, experiences, opinions, and feelings (Mack, 2005).

\section{Respondents}

A total number of twenty (20) respondents from Penang who have drug abuser in the family were selected to participate in this study based on these four main criteria: (1) the respondent must be the head of the family, (2) the respondent are from either of nuclear family, extended family or single parent family, (3) the respondent must live in and take care of their drug abuser family members for at least one year, and, (4) they must be at least eighteen (18) years old and above. Location for the interview were selected by the respondents based on their preference and choice either at their own home or at Penang National Anti-Drug Agencies.

\section{Data Collection}

A semi-structured interview using an in-depth interview technique to gather the data is used in this study for data collection. Each interview takes an approximately of 45 to 90 minutes to complete. The medium of language used in conducting the interview was in Malay.

\section{Data Analysis Procedure}

Data collection for each interview were transcribed and reviewed for at least two times by the researchers in order to ensure its accuracy and correctness to ensure the data remains binding of its 
original meaning. The transcribed data were labelled accordingly to identify its meaning, and later segregated into its groups relating to the constructed emerging themes and sub-themes.

\section{Ethical Considerations}

As to maintain a strict discretion of the data and information of the interviews, an approval was obtained beforehand from the Universiti Sains Malaysia ethics board (USM/JEPeM/16110485) prior to the commencement of study. A signature of consent were attained from respondents in a written format after a briefing was conducted informing them about the discretion of the information given in the interview. In the briefing, the respondents were explained in details about the main objectives of the study and their right to discontinue the interview and/or withdraw from the study at any time without any penalty. In order to ensure anonymity and confidentiality, statements made by the respondents were coded. Providentially, all respondents in this study were fully committed and collaborated well throughout interviews.

\section{Findings}

The findings of this study indicated that the respondents implemented both problem-focused and emotion-focused coping strategies. For instance, coping strategies such as assertive, supportive, inactive, avoidance, emotional and controlling was implemented in order to deal and cope with the drug addiction problems especially on the drug abuser in the family. The findings also further indicated that respondents frequently used both formal and informal social support systems to cope with the problem.

\section{Assertive Coping}

The respondents of this further explained that they also had applied assertive coping strategies to deal with the drug abuser in their family. Majority (18) of the respondents said that they have openly expressed their intolerance to the drug abuse by the drug abuser in the family and in addition, the respondents also conferred the set of circumstances and drug problems openly with the abusers.

\section{Supportive Coping}

All of the (20) respondents have implemented supportive coping to deal with the drug problem in their family and this includes supportive coping such as being with the drug abuser, sitting down together and talking heart to heart, comforting and offering helpful and supportive advice for them to overcome the drug problem gradually.

\section{Inactive Coping}

Another frequent feedback received from the respondents in this study was the use of inactive coping. There were (7) respondents in this study who specified that they did not take any appropriate action to address the drug problem in the family because they felt too terrified to response, reluctant to get involved, were unsure how to react, did not know what to say / speechless and want to get rid of the problem.

\section{Avoidant Coping}

Of the (20) respondents, (6) respondents have taken action by keeping a physical distance between them and the drug abuser family member by getting away from the abuser by way of leaving home, not talking to them, staying in a different room and telling the drug abuser to leave the house and basically to avoid bumping in or meeting the abuser. 


\section{Emotional Coping}

Most (19) respondents expressed explicitly their negative emotions such as shouting, yelling, losing their temper, arguing, quarrelling, nagging, challenging, threatening and struggled physically the drug abuser in the family as to show their emotions of dislikes towards the drug addiction.

\section{Controlling Coping}

A total of (9) respondents described that they actually take control on the amount of drugs taken by their drug abuser family member via careful observation on the abusers and do not leave them alone at home at any cause.

\section{Formal and Informal Social Support Systems}

The respondents on the other hand had applied formal and informal support system, such as their getting motivation, support and advice from immediate families and counsellors from the National Anti-drugs Agency. This study showed that (8) respondents have met counsellors from the National Anti-drugs Agency to find the effective ways to cope and deal with the drug problems in the family. Furthermore, the results of this study also found that all (20) of the respondents have attained emotional support from their family members, relatives, neighbours, friends of the other drug abusers' families, as well as spiritually praying and seeking help from God to cope with the drug abuse within their family.

\section{Discussion and Conclusion}

Findings of this study indicates that respondents used six types of strategies to cope with the drug abuse within their families. The six types of coping strategies are i) assertive, ii) supportive, iii) inactive, iv) avoidance, v) emotional and vi) controlling coping strategies. Most of the respondents in this study exposed that they had expressed their hatred feelings towards the abuse of drug by their drug abuser family member. Lee et al. (2011) exposed that in most of the drug abuse cases, drug abusers' failed to find emotional coping to be supportive. Emotional coping actions typically includes the expression of negative emotions in order to make realize the drug abusers that their family members were upset with their behaviour and attitude due to the drug abuse. This eventually will led the drug abuser to feel guilty which will encourage them to change, but unfortunately, in this study it was revealed that most drug abusers do not care about the emotional coping and found to be ineffective.

The findings also revealed that some of the respondents used avoidance and inactive coping strategies to deal with the drug abuser in their family by often distance themselves from the drug abuser. For instance, one of the respondents in the interview revealed that he refuse to go home and would rather stay in the hostel where he worked because he wanted to stay away from his drug abusing son because too terrified of getting hurt. As to support the aforementioned findings the studies conducted by Murphy (2002) also stated that the family members of drug abuser were found to distance themselves physically and emotionally from their family members who abused drugs. A research by Lee et al. (2011), explained further that in majority of cases, drug users found that avoidance and inactive coping were unable help them to change their addictive behaviour because the abusers felt that their family members were avoiding them and refuse to discuss about their drug problems. This is known as an unsupportive coping.

The results of this study also exhibited that some of the respondents were strictly monitoring, controlling the movements and attitude of the drug abuser in their families. This study finding is consistent with what has been emphasized by Lee et al. (2011). Drug abusers dislikes the controlling coping actions and found it to be unsupportive. They dislikes the fact that someone, especially their own family members controlling their activities and movements. This type of coping unlikely to help them to reduce or giving up the use of drugs or to seek treatment (Lee et al. (2011)). This study also found that More than half of the respondents in this study emphasised that they strictly prohibits the 
amount of drugs consumed by the drug abuser. Prior to this, the respondent's family members often make annotations about the drug abuser's appearance by telling them that they don't look good or articulating concern about the drug abuser's health condition. This type of strategy is known as an assertive coping and most of the research findings indicated that the drug abuser found this type of coping to be supportive in reducing the use of excessive drug substance.

All of the respondents in this study explained that they had rendered full support to the drug abuser in their family by all efforts. For instance, some of the respondents said that they frequently provide emotional support and does not give up easily on the drug abuser because they believed that the drug abuser requires this kind of support in order for them to change gradually. The findings of this study is comparable with previous studies completed by (McDonald, Russell, Bland, Morrison, \& De la Cruz, 2002; Murphy, 2002). On the other hand, this study also found that the respondents had fully utilized resources and support systems to cope and deal with the drug abuse in their family. For instance, some of the respondents attained emotional support from their immediate family members, relatives, neighbours, friends and other drug abusers' families, as well as spiritually praying and seeking help from God to cope with the drug abuser family member. According to Krishnan, Orford, Bradbury, Copello, and Velleman. (2001) the drug abuser's family members felt supportive and motivated when they were able to talk and share the drug problems in their family with their immediate family members. In addition, some of the respondents had also obtained social support from the counsellor at the National Anti-drugs Agency to help and assist them in understanding and finding out in about the fundamental causes of the drug problems faced by their drug abuser family member.

Last but not least, the findings of this study suggests several steps that can be implemented by the family members of those drug abusers. For instance, they should consider engaging in self-help and support groups. Obviously by involving themselves in these types of groups, they would be able to learn about constructive coping strategies that is used by other families who have encountered similar problems and experience in dealing and confronting with the drug abuser in their family. This study strongly recommends the government agencies, particularly the National Anti-drugs Agency and nongovernmental organizations (NGOs) continue to provide appropriate trainings related to coping strategies for drug abuser family members. This training is important in order to enhance their existing knowledge in implementing the coping strategies when dealing with drug abuser family member.

\section{Acknowledgement}

The authors would also like to thank all the respondents who consented to participate in this case study. This work was supported by the Universiti Sains Malaysia Short Term Research Grant (304/PSOSIAL/6315049).

\section{References}

Barnard. M. ( 2005). Drugs in the family: The Impact on parents and siblings. University of Glasgow: Joseph Rowntree Foundation.

Butler, R., \& Bauld, L. (2005). "The Parents' Experience: Coping with drug use in the family" Education, Prevention and Policy, 12 (1), 35-45.

Fisher, M. (2007). Supporting families and carers of drug users: A qualitative study. Scotland: Effective Interventions Unit.

Franco, V. (2010). Family effects of drug abuse. Retrieved from http://www.lives trong.com/article/89757-family-effects-drug-abuse/.

Harbin, F., \& Murphy, M. (2000). Substance misuse and child care: How to understand, assist and intervene when drugs affect parenting. Lyme Regis: Russell House Publishing.

Krishnan, M.Y.A., Orford, J., Bradbury, C., Copello, A., \& Velleman, R. (2001). Drug and alcohol problems: The 'users perspective on family members coping'. Drug and Alcohol Review, 20, 385-393. 
Lee, K.M.T., Manning, V., Teoh, H.C., Winslow, M., Lee, A., Subramaniam, Y., Guo, S., \& Wong, K.E. (2011). Stress-coping morbidity among family members of addiction patients in Singapore. Drug and Alcohol Review, 30, 441-447.

Mack, N. (2005). Qualitative research methods: A data collector's field guide. New York: Family Health International Publication.

McDonald, D., Russell, P., Bland, N., Morrison, A., \& De la Cruz, C. (2002). Supporting families and carers of drug users: A review. Scottish Executive: Effective Interventions Unit.

Morris, G. (2010). Bad effects of drug addiction. Retrieved from http://www.livestr ong. com/article/243268-bad-effects-of-drug-addiction/.

Murphy. L, J. (2002). Fighting Back: Women and the Impact of drug abuse on families and communities. Dublin: Liffey Press.

Oreo, A., \& Ozgul, S. (2007). Grief experiences of parents coping with an adult child with problem substance use. Addiction Research and Theory, 15 (1), 71-83.

Toumbourou, J. W., Blyth, A., Bamberg, J., \& Forer, D. (2001). Early impact of the best intervention for parents stressed by adolescent substance abuse. Journal of Community \& Applied Social Psychology, 11, 291-304. 